\title{
Obra musical opaca: a confluência de valores da música experimental em Pierre Schaeffer e John Cage
}

Alexandre Sperandéo Fenerich*

RESUMO: O texto compara posições estéticas de Pierre Schaeffer e John Cage com respeito à música experimental, tentando confluir, de seus percursos distintos, os sentidos iniciais ligados ao adjetivo.

PALAVRAS-CHAVE: música experimental; Pierre Schaeffer; John Cage; musique concrète; Le Corbusier

ABSTRACT: The text compares aesthetic positions of Pierre Schaeffer and John Cage in concerning to experimental music, in order to converge, from their distinct routes, the initial meanings connected to the adjective.

KEYWORDS: experimental music; Pierre Schaeffer; John Cage; musique concrète; Le Corbusier

\footnotetext{
*Alexandre Sperandéo Fenerich é professor do Instituto de Artes e Design da Universidade Federal de Juiz de fora - IAD - UFJF. Doutor em musicologia pela USP (2012) é compositor e sound designer com pesquisa sobre a relação entre música concreta, intimidade e voz. Trabalha com composicão musical sobre mídias digitais, com foco em live eletronics, espacializacão aural e performances audiovisuais ao vivo. Participou de projetos internacionais na Alemanha, em Portugal e no Brasil, além de diversos festivais de música e artes digitais (Festival Ibrasotope, Live Cinema, ZKM, Münchener Bienalle, Futura (France), Beliner März Musik), além de desenvolver trabalhos com diretores de cinema, dançarinos, artistas visuais e teatrólogos.
} 
O percurso deste texto tenta mostrar como, de maneiras totalmente distintas, dois expoentes centrais da música de vanguarda dos anos 50 e 60, Pierre Schaeffer e John Cage, confluíram para valores musicais semelhantes, distanciando-se de uma vanguarda ligada à tradição da música ocidental - o serialismo integral - e fundando princípios, procedimentos e técnicas musicais que se solidificariam ao redor do termo experimental. O artigo tem assim o caráter de fazer confluir caraterísticas comuns a esses dois autores, a fim de delimitar os sentidos iniciais ligados a esse adjetivo.

Em um artigo que explicita e contextualiza o nascimento da palavra experimental associada à palavra música em textos do autor francês de meados da década de 50, Carlos Palombini conclui: "Em relação à música concreta, a música experimental correspondeu à necessidade de generalizar a abordagem concreta, de abri-la a novos sons e novas técnicas, de reavaliar seus princípios e definir seu método." (Palombini, 1998, p. 14)ำ Na transição entre música concreta e experimental, um forte valor musical, que seria agregado à própria ideia do experimentalismo em música, é indicado: um passo atrás com relação ao acabamento formal que delineia tanto a noção de autoria quanto de obra. Pierre Schaeffer explicita esta tendência já em gestação na época das composições "concretas", em texto que aborda a virada destas para uma "música experimental", a ser inventada:

Considerando que a descoberta de objetos sonoros era primordial, que era necessário primeiro fabricá-los em grande número, determinar suas categorias e famílias, antes mesmo de saber como eles podiam evoluir, ser reunidos e combinados entre si, eu procurava impaciente músicos bastante bons e bastante desinteressados para ousar este trabalho gigantesco, que mais se assemelhava ao do botânico do que ao do compositor. Devo dizer aqui que sem a presença de Pierre Henry, ainda que ele também [fosse] tentado pela construção serial, a música concreta provavelmente tivesse carecido de um experimentador essencial. Tão essencial que ela poderia ter nascido morta e, mal descoberta, já se ter, por assim dizer, perdido. Em vez de ser o ponto de partida de um procedimento musical mais geral, do que estou quase certo agora, ela não teria sido mais que o prolongamento árido e provavelmente efêmero ou do surrealismo ou da música atonal. (Schaeffer apud Palombini, 1998, p. 4). 
Sobre este aspecto, o conceito "música experimental" é uma saída para frear uma afoita solidificação da pesquisa musical em "obras" - tanto pela construção livre das composições anteriores que conduziam a narrativas sonoras (a partir do uso de sons com forte carga referencial, "surrealismo") - que, para Schaeffer, tinham mais o caráter literário que musical (Palombini, 1998, p. 6) - quanto pela serialização de parâmetros aplicados aos "materiais concretos" (isto é, aos sons gravados) - técnica empregada por compositores ligados ao serialismo integral que haviam frequentado até então (estamos em 1954) o estúdio do Grupo de Pesquisas de Música Concreta (como Messiaen, Boulez e Grunenwald) - a qual, na sua opinião, constrangia a aventura pela pesquisa sonora ${ }^{2}$. Pierre Henry parecia, pelo menos temporariamente, corresponder à vontade do diretor do grupo de pesquisas, explorando meticulosamente o instrumentário da música concreta e suas novas sonoridades.

Para o caminho que gostaria de trilhar nesse texto, a percepção de Schaeffer de que o serialismo integral era uma solução demasiado rápida e extrínseca ao material sonoro concreto é significativa. Esta opinião apareceria do choque entre metodologias opostas no dia a dia do estúdio que dirigira (as ligadas às práticas concretas e as ligadas à música serial). O serialismo guarda uma forte conexão com a tradição musical do Ocidente, no qual o arbítrio do compositor sobre o material é soberano. Nele,

A forma musical (i.e., a tradição) tem precedência sobre a forma sonora. Tanto Boulez quanto Eimert parecem sugerir que não é pelo fato de haver novos sons disponíveis que novas formas musicais se tornam possíveis, mas pelo fato do compositor ter necessidade de novas formas musicais que novos sons aparecem. (Palombini, 1998, p. 12)

A proposta schaefferiana, por sua vez, tendia, naquele momento, a explorar com mais consistência o universo sonoro aberto pelas práticas concretas, do qual "mal acabara de compreender e [se] espantar" (Schaeffer apud Palombini, 1998, p. 5). Um processo a seu ver que havia sido iniciado, mas que fora truncado, tanto por abordagens composicionais demasiadamente ligadas às necessidades expressivas dos autores (no seu caso e no de Pierre Henry), quanto pela aplicação do método serial a materiais concretos, que na sua opinião, "destrói-lhes o frescor" (Schaeffer apud Palombini, idem, ibidem).

A defesa de um empirismo na abordagem das sonoridades e de uma "submissão ao achado" (Schaeffer apud Palombini, idem, ibidem) levaria a uma valorização, mais que da realização de 
obras, do processo de aprendizagem a partir deste novo universo. Em um texto de 1957 - e portanto posterior à formulação da ideia de uma "música experimental", Schaeffer se dá conta do real legado daquilo que inventara:

O aporte da música concreta naquilo que ela pode ter de revolucionário não tem relação com o fato dela fazer uso de aparelhos modernos, nem mesmo ao fato de que ela talvez traga à escuta sons até então inauditos. Mas tem relação com o fato de que, ao organizá-los nas obras e nos ensaios - mesmo discutíveis - ela propôs uma escuta musical de objetos sonoros que não faziam parte do domínio musical definido pela tradição. Da mesma forma, ao colocar em um outro contexto os objetos sonoros que foram também sons musicais reconhecíveis como tais, ela atrai a atenção para certas qualidades destes objetos, qualidades de forma, por exemplo, que, em uma composição clássica, baseada em uma dialética das alturas, passaria ao segundo plano. Ao fazê-lo, ela convida autores e ouvintes a uma expansão da escuta musical, revelando possibilidades aos ouvidos musicais que certamente já existiam, mas que antes eram pouco percebidos ou pouco explorados. (Schaeffer: [1957] 1970, p. 196)

Sua conclusão é decisiva para a delimitação que gostaria de trabalhar aqui: quando menciona que, mesmo empregando sons com referências aos instrumentos clássicos (como na Suite $n^{\circ} 14$, por exemplo), não os organiza de acordo com a "dialética das alturas", Schaeffer se refere a um campo de trabalho que está fora dos domínios tanto da escrita musical, quanto de métodos tradicionais de composição - dos quais o serialismo faz parte por se vincular ao dodecafonismo. Em outras palavras, poderíamos dizer que aquilo que o "experimental" se refere em Pierre Schaeffer é o sonoro por inteiro dos sons gravados - os quais constituem os sons concretos - e que abre um campo radicalmente diferente para a pesquisa e a criação musical com relação aos meios tradicionais ou históricos (pois não se trata, por outro lado, de um registro oral da cultura musical, pois os meios de gravação sonora permitem a re-escuta do material gravado, sua análise e sua resignificação, ao contrário daqueles). Um campo portanto essencialmente sonoro - e não regido por certos aspectos do sonoro, pré-selecionados pela notação ou por métodos tradicionais - ao qual compositores e técnicos, transformados em 'pesquisadores', deveriam se voltar, mergulhados na radicalidade da experiência que proporciona.

Trata-se de um projeto utópico, o qual seria traído pelo seu próprio inventor. Sabe-se que a morfo-tipologia do objeto sonoro, exposta muito mais tarde no Traité des Objets Musicaux, de 1966, é um método de análise do objeto sonoro - este ente gravado, escutado fora de 
suas referências causais, linguísticas ou musicais. E um método talvez tão extrínseco ao material sonoro quanto o serialismo, por consistir em uma grade demasiado genérica a enquadrar os objetos sonoros. No entanto, não nos interessa pontuar os fracassos da empreitada iniciada nos textos de meados da década de 50, mas apontar sua potência nesse momento de gestação da ideia. Pois em texto de 1957 Schaeffer propõe, sinteticamente, algo que me parece significativo:

A pesquisa se orienta assim para esta via: um treinamento metódico da escuta, análoga à do solfejo tradicional, mas generalizado. É por ela que músicos e ouvintes poderão se apropriar progressivamente dos novos domínios (Schaeffer, idem, ibidem).

Há, assim, um projeto de criação que passa por uma pedagogia da escuta a partir da radicalidade deste novo meio, O trabalho com loops, por exemplo, fora já um esboço desta pedagogia: o mergulho nos mantras gerados pelos sons em loop criava um "aprofundamento da escuta ao interior da mídia pela interrupção do fluxo temporal e focalização no evento separado pelo loop" (Fenerich, 2012, p. 122) - um dispositivo que isola o fragmento, rasgando-o da temporalidade do som originalmente gravado ${ }^{3}$.

Este fora usado como recurso de repetição ou de pedal rítmico nas primeiras obras da música concreta, mas é a partir de reflexões posteriores, como as relativas à modificação, diríamos, da qualidade da atenção frente ao objeto sonoro em loop - a alteração da temporalidade "normal" dos eventos, sejam gravados ou não - que o projeto de música experimental parece se formular.

Em um percurso que vai, inicialmente, do deslocamento do uso comum de aparelhos radiofônicos que proporcionaram a criação de "estudos de ruído"4; em seguida, da proposição, a partir desta experiência e do aparato técnico que inventara (com o técnico Jacques Poulin), de obras musicais; e adiante, da abertura para que outros compositores experimentassem com estas técnicas, tentando com isso realizar uma síntese das diversas tendências de então, Pierre Schaeffer parece aportar, no final da década de 50, em um outro tipo de trabalho com sons no campo fértil que instaurara: não mais a produção de obras musicais - uma necessidade burocrática inicial em um projeto financiado por uma rádio estatal que esperava por material irradiável, a qual fora certamente suplantada pelo seu crescente prestígio (Cf. Palombini, 1998, p. 17) - nem o esforço por sintetizar as diversas técnicas, mas a assunção 
de um projeto pedagógico da escuta a partir das criações realizadas no campo da tecnologia voltada para o som.

É significativo que os desvios iniciais do uso comum das máquinas ligadas ao rádio tenham ocorrido, conforme Schaeffer, como um erro de operação posteriormente incorporado como descoberta sonora: o loop, por exemplo, teria sido resultante de um sulco fechado decorrente de um erro na gravação normal dos discos de acetato (primeira mídia com a qual trabalharam) que, isolando um "fragmento sonoro", faz o sulco, que na gravação normal seguia em espiral, "morder o próprio rabo", realizando um círculo cujo final coincide com seu início (Schaeffer, 1952, p. 40). Foi uma alteração do projeto original da "caixa preta" dos dispositivos radiofônicos (para utilizar um conceito de Flusser: 2012), que resultaram em situações que abriram "um repositório de potencialidades musicais inimaginadas" (Palombini, 1998, p. 13). A música experimental para Pierre Schaeffer no final da década de 50 parece ser, então, o exercício da descoberta, tanto de sonoridades inauditas, quanto destas potencialidades musicais cuja ignição se deu pela pesquisa de desvio tecnológico efetuada nas primeiras práticas concretas.

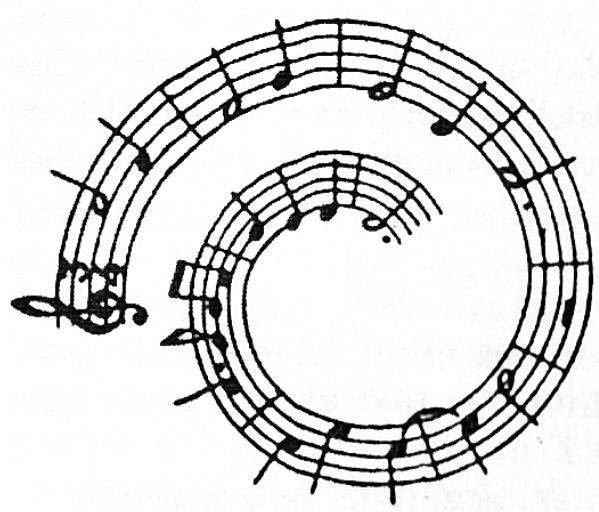

fig. 3 .

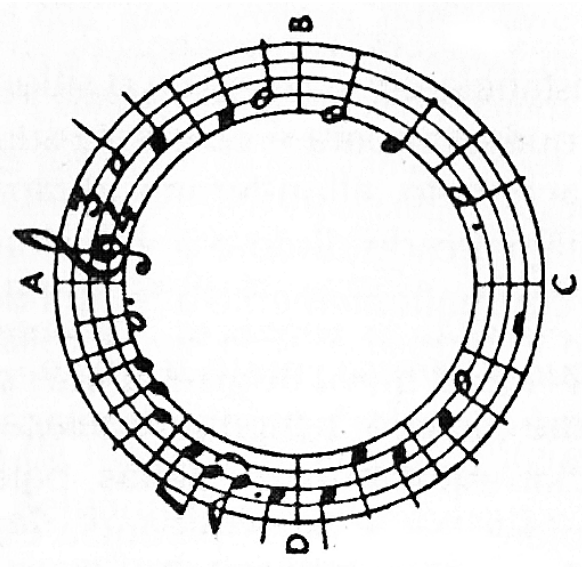

fig. 4 .

Sulco aberto e sulco fechado (Schaeffer, 1950, p. 40) 
Remeto-me agora a um texto de John Cage que me parece dialogar com a aventura schaefferiana: Rhythm etc, publicado em $1966^{5}$. Aqui o autor gira entorno de uma ideia central - imanente, mas nunca explicitada: a oposição direta à noção, proposta por Le Corbusier em 1948, do Modulor - princípio ordenador de formas arquitetônicas cujas proporções derivam da razão áurea ${ }^{6}$ (Possebon, 2004) 7 .

Cage se opõe ao Modulor de Le Corbusier por entendê-lo sistêmico, autoritário. Em seu artigo, ele o cita, dando-se ao direito de omitir e sublinhar trechos:

acordo entre homens e máquinas, sensibilidade e matemática, uma colheita de harmonias prodigiosas a partir de números: a rede de proporções. Essa arte... será conquistada pelo esforço dos homens de boa vontade, mas será contestada e atacada.... Ela tem de ser proclamada por lei" (Le Corbusier apud Cage, 2013, p. 126)

Trata-se do momento mais veemente do texto de Cage contra Le Corbusier, mas que, paradoxalmente, é uma citação deste último. O trecho sublinhado por Cage é indicativo daquilo ao qual se opunha: a normatização da regra de ouro - uma revolta contra um pensamento platônico por calcado em uma perfeição geométrica e que, por isso, se auto-proclama legítimo.

Pois, além disso, por estipular que a proporção áurea é também encontrada entre as partes de uma figura humana com um braço levantado, relacionando esta regra matemática com as dimensões humanas - o Modulor, tido como sistema ideal por conciliar equilíbrio matemático com as formas humanas, foi utilizado por Le Corbusier e arquitetos associados como modelo para o projeto de edifícios a serem produzidos em série na era industrial (Le Corbusier apud Possebon, 2004, p. 6). 


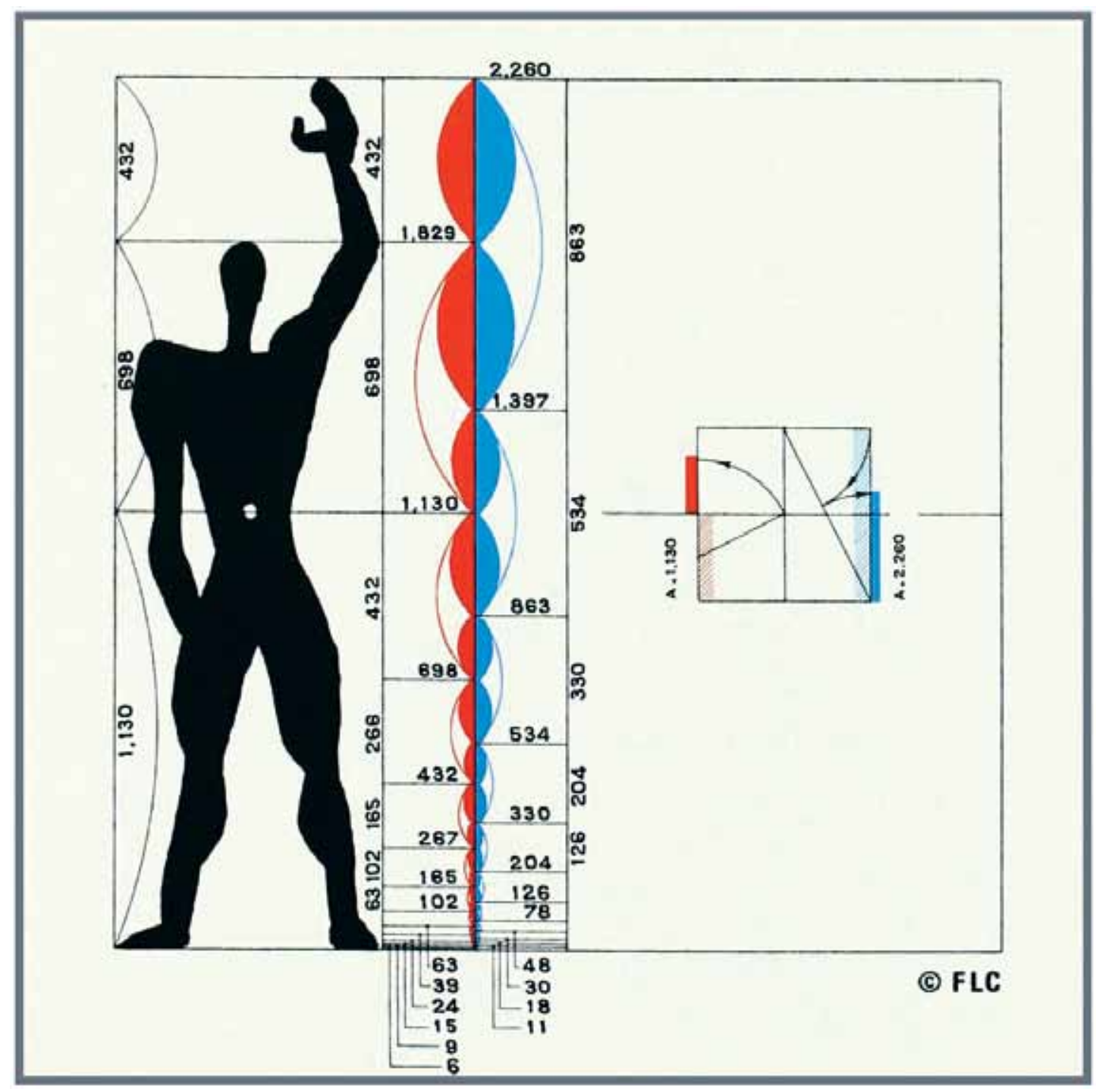

Le Corbusier

Modulor 
A essa normatização, Cage reage:

Isso é chamado Arte. Sua forma é a tirania. A inflexibilidade social decorre da concepção inicial da proporção. A linha desenhada entre dois pontos torna-se primeiro um entrelaçamento, e finalmente tridimensional. A menos que encontremos um caminho de saída, estamos perdidos. (...) Não proporção. A desordem da floresta virgem. (CAGE, idem, ibidem)

Sua oposição é uma afirmação: contra uma concepção inicial (e portanto, a priori) da proporção. O momento é o de reação às vanguardas europeias ligadas ao serialismo integral, e o artigo fora escrito originalmente para um livro destinado ao estudo do ritmo e das proporções "naturais" ${ }^{8}$, sendo o contrário do que se esperava; opõe-se à simetria e às proporções intrínsecas em arte. Contra a simetria, ele reclama: "Quando eu vejo tudo que está à minha direita se assemelhar a tudo que está à esquerda, eu me sinto da mesma forma como me sinto em frente de algo em que não há nenhum interesse". (Cage, 2013, p. 121) Contra as proporções à priori a fim de facilitar as produções industriais: "Não me diga que é uma questão de produção em massa. Não seria, antes, que eles querem estabelecer, se não as regras do jogo, ao menos aquilo com que as pessoas costumam jogar, quando começam a jogar?" (Cage, idem, p. 123) Etc.

A questão de fundo é política. Para Cage, o sistema proposto por Le Corbusier é autoritário: impõe um modelo matemático à construção por considerá-lo belo em si; reforça que esta beleza seria natural por basear-se nas proporções do corpo humano. Pois este corpo é ideal, e não concreto; e essa proporção, extrínseca à paisagem. Está, portanto, nos olhos de quem vê: "Como, em nome dos céus, alguém pôde ter a ideia de que a proporção ocorresse fora de sua cabeça?" (Cage, idem, p. 130) O artigo opina que a arte europeia, em sua arbitrariedade, incrusta esta forma idealizada em tudo que realiza:

ele não tinha cometido erros: era só que as circunstâncias eram esmagadoramente diferentes da ideia com a qual ele estava tentando disfarçá-las. E sua ideia, realmente, disse ele, era uma ferramenta, um instrumento - não um objeto. (...) Não uma ferramenta, mas um instrumento, como o piano, que, quando usado, deixa suas notas espalhadas por toda a música que foi tocada. (Cage, idem, p. 124)

O texto de 1966, que retoma muitas ideias de Cage a respeito do uso de ruídos na música e da sua abordagem do acaso e da indeterminação, parece justificar estas abordagens. A utilização de tecnologias não-colonizadas pela cultura musical (como a gravador, o microfone 
de contato ou o sintetizador ${ }^{9}$ ) é uma resposta a esta necessidade de "abandonar as notas". Há assim, como em Schaeffer, uma vontade de abertura para sons inauditos. Por outro lado, o que se discute aqui é uma postura de negação de postulados estéticos preestabelecidos (tal qual a razão áurea). Nesse sentido, tanto a nota musical, "unidade mínima" da música ocidental - entidade complexa se considerada em seus componentes espectrais - quanto a série dodecafônica, organização totalmente centrada na noção de nota, são negados. A nota musical carrega uma delimitação sonora tanto de matéria (para usar uma terminologia schaefferiana - ou seja, se prescinde do tempo, algo que permanece - no caso, uma sensação de altura definida), quanto da forma (concernentes à evolução da matéria no tempo: um ataque definido, um decaimento e um fim). A teoria musical do século XIX teria postulado que a sensação de "nota" deve-se a um princípio natural relativo aos parciais (ou componentes sonoros com maior pico de amplitude) cujas frequências formam entre si uma relação de números inteiros - sendo essa a justificativa desta sensação ${ }^{10}$. A série dodecafônica, por sua vez, seria a conquista da música européia "dos parciais harmônicos superiores" por via da sistematização do total cromático por via de sua serialização (tal qual postulara Webern e Shoenberg ${ }^{11}$, respectivamente, discípulo e criador do dodecafonismo). Ambas as categorias estão, portanto, calcadas numa noção de natureza muito semelhante àquela postulada por Le Corbusier. Essa ideologia do "natural" conteria para Cage o caráter autoritário o qual pontuamos.

Por outro lado, a abertura para a realização livre do intérprete (dada pela indeterminação) é outra mensagem imanente do texto: como adverte no preâmbulo de início, este tem como "principais personagens" Le Corbusier e o pianista David Tudor - responsável pela criação de muitas obras de Cage - homenageado no preâmbulo. Em uma curta sequência, Cage enumera em três etapas seu abandono da "nota", metáfora de uma sonoridade a ser esperada ou previsível quando de sua composição (tal qual ocorre na música ocidental tradicional):

a) Usamos operações ao acaso. Vendo que eram úteis somente onde havia uma limitação definida do número de possibilidades, b) usamos composição indeterminada em relação à sua execução (caracterizada em parte pela independência das partes de cada executante - sem partitura). Vendo que isso só era útil quando havia chance de conscientização da parte de cada executante, c) usamos execução indeterminada em si mesma. (Cage, idem, p. 130)

Aqui, os itens b e c são decisivos: na poética cageana, há um progressivo abandono do controle dos gestos dos intérpretes por parte do compositor por meio de notações indeterminadas cada vez mais descoladas de uma relação entre o signo verbal ou gráfico e uma sonoridade 
ou ação específicas. É claro que a liberdade dada ao intérprete é relativa: este a teria apenas se for "conscientizado" - ou seja, se adepto da estética cageanana do uso de silêncios, do predomínio de ruídos, e sem arroubos de interpretação (como o uso descontrolado de vibratos, por exemplo) - como se pode observar em toda a sua obra ${ }^{12}$ - sendo David Tudor o meIhor parceiro para estas empreitadas musicais. Liberdade concedida, portanto ${ }^{13}$. Mas, ainda assim, assiste-se a um progressivo abandono de qualquer elemento que garanta uma noção de obra fechada - muito embora, nesse período, os intérpretes tocassem uma peça qualquer de Cage "com execução indeterminada em si" que na prática era uma improvisação ao estilo da música do compositor.

Comparando as trajetórias de Pierre Schaeffer e John Cage, que, chegando no termo "música experimental," afluem para valores musicais semelhantes, podemos traçá-las a fim de entender conceitualmente suas proposições musicais. Em ambos os casos, tem-se um distanciamento da notação musical baseada em parâmetros tradicionais, como a nota e os ritmos proporcionais. No caso de Schaeffer isto parece óbvio desde o início, sendo que no caso de Cage isto foi alcançado progressivamente pela construção de que esta notação encerrava uma ideologia que, no limite, continha um caráter autoritário. No entanto, junto à negação da notação enquanto um "faça isso", também se encontra uma vontade de descoberta de sonoridades novas - as quais as notações tradicionais não conseguem traduzir - dadas pelo uso das modernas tecnologias sonoras.

Uma comparação da concepção de tecnologia para ambos os autores fugiria do escopo deste artigo, mas sou tentado ao menos a apontá-la aqui. Concluí o trecho sobre Schaeffer sugerindo que sua abordagem inicial da tecnologia, na primeira música concreta, ia no sentido de descobrir usos inexplorados ou não previstos dos aparelhos ligados à produção radiofônica que tinha em mãos, em 1948 (surgimento da música concreta). Trata-se assim de um uso da tecnologia que, de início, a toma como não-neutra, ou como algo a ser manipulado nas suas fendas, naquilo que tem de "inútil" por não previsível.

Em Cage esta tecnologia tem um outro caráter: são ferramentas que não deixam traços no sonoro; "coisas a serem usadas, que não determinam necessariamente a natureza do que foi feito" (Cage, idem, p. 124) - ao contrário do piano, que, como já apontamos, para ele "deixa 
suas notas espalhadas por toda a música que foi tocada" (Cage, idem, ibidem) - ou seja, traz para o sonoro as marcas da cultura ocidental por conta da afinação temperada e do perfil temporal (notas). Assim, em Cage há uma crença na neutralidade dos instrumentos modernos com relação à sonoridade que transduzem - polo inverso com relação a Schaeffer.

Para este, as características dessa tecnologia determinam abordagens do sonoro: a gravação permite a reprodução objetiva do evento gravado por repeti-lo de modo idêntico e por deslocá-lo da temporalidade normal; o loop permite um deslocamento temporal do fragmento sonoro, repetindo-o; o microfone transduz detalhes ínfimos do som; etc. A tecnologia não é, então, neutra, mas traz potencialidades.

O que há em comum nesse campo para ambos é, a meu ver, a crença de que, pela tecnologia, se aporta em lugares inexplorados sonoramente. Em Schaeffer, essa crença parece ser ainda mais intensificada pelo fato de, além indicar novas sonoridades, ela permitir descobertas perceptivas (como as relacionadas ao loop, como apontamos) e indicar metodologias de pesquisa. Não se trata de um ente distanciado da pesquisa musical, mas algo a ser desenvolvido paralelamente a ela. Mas curiosamente, em ambos há uma certa autonomia da tecnologia com relação à criação musical: em Schaeffer esta serve como um "país fértil" inesgotável, cuja pesquisa pode abrir para campos desconhecidos, enquanto que para Cage é um transdutor neutro que permite com que apareçam gestos inusitados dos músicos e pesquisas inéditas dos materiais (proporcionadas, por exemplo, pelo microfone de contato - muito usado por Cage e outros músicos da música experimental americana - que capta, dentre outras coisas, as irregularidades das superfícies dos objetos, quando friccionados a eles).

Esta abertura para a tecnologia enquanto meio autônomo é espelhada a uma abertura, em ambos os autores, a um campo do sonoro não mediado nem pela notação, nem pela acústica ou por técnicas ligadas à tradição da musical ocidental. Este aspecto leva, em ambos, a uma noção de pesquisa do sonoro que, em Schaeffer, tem um caráter pedagógico, e em Cage, um caráter político. De qualquer forma, eles chegam, por conta desse aspecto, a uma noção de abertura da obra musical; da negação do encerramento do trabalho em obras fechadas em função de uma postura de escuta, a qual influenciará profundamente seguidores como Luc Ferrari e Bernard Parmegiani (no caso de Schaeffer) e Alvin Lucier e Steve Reich (no caso de Cage) - que, embora realizassem obras fechadas, possuíram, em seu trabalho, uma força de 
descoberta de processos extrínsecos à vontade composicional (e portanto à tradição) - a delimitação de aspectos do sonoro a serem partilhados. Nesse sentido, o experimental possui uma qualidade de descoberta do som quase como que de uma entidade que fora mascarada ao longo da história da música ocidental, tanto pela especialidade do sonoro para a qual confluíram instrumentos, técnicas, afinações etc, quanto pela forte presença autoral, que teria solapado a escuta em função da expressão. E nisso, tanto a pesquisa de Schaeffer quanto de Cage parecem confluir.

\section{Notas}

1 O termo "música experimental" nasceu de um esforço de Pierre Schaeffer de "comparar métodos e estabelecer programas de pesquisa" (Palombini, 1999, p. 6) entre musique concrète, elektronische Musik, music for tape e as "músicas exóticas" (estas últimas consistindo, para o autor, em músicas realizadas por instrumentos não-tradicionais (como o piano preparado) ou oriundos de civilizações ou povos não-ocidentais - cf. Schaeffer, 1966, p. 19). Entretanto, os textos de Schaeffer que abordam essa tentativa (Vers une musique experimentale e Lettre à Albert Richard) estão cheios de contradições que apontam, não para um sincretismo (para utilizar a expressão de Palombini: 1998, p. 13), mas para uma progressiva delimitação do termo "música experimental" no sentido que, no meu entendimento, exporei aqui.

2 "Da série de doze notas fica uma vontade construtivista que, aplicada talvez prematuramente aos novos materiais, destrói-lhes o frescor. A floração de sons concretos arrisca-se a ser colhida muito cedo quando se toma partido pela abstração. Os resultados são contraditórios ou decepcionantes" (Schaeffer apud Palombini, 1998, p. 6).

3 Palombini assim se refere ao achado Schaefferiano, no modo como the aparecera de início: "Sons assim isolados pareciam a ele tal qual palavras no estado de liberdade que apresentam no dicionário: separadas de seu contexto (descontextualizadas), elas eram escutadas por si próprias". (Palombini, 1993, p. 17).

4 Refiro-me aqui aos Cinq Études de Bruits, primeira série de obras compostas por Pierre Schaeffer sob este viés, em 1948.

$5 \mathrm{O}$ texto fora editado primeiramente no livro Module Proportion Symmetry, Rhythm, organizado por Gyorgy Kepes em 1966. Fora lançado novamente em 1967 na coletânea de artigos A Year from Monday, livro de 1967 (Cage, 2013) - o qual fora traduzido para português pelo músico Rogério Duprat e lançado primeiramente no Brasil em 1985 (idem, ibidem). O texto o qual nos baseamos está na sua segunda edição brasileira, de 2013.

6 A razão áurea é a proporção derivada das divisões de uma reta em duas, de tal modo que o segmento menor esteja para o maior assim como o maior esteja para o todo. Cf. https://pt.wikipedia.org/wiki/Divis\%C3\%A3o_em_m\%C3\%A9dia_e_extrema_raz\%C3\%A3o, acesso em 18/08/2015.

7 Para um estudo da crítica de Cage a Le Corbusier em diálogo com uma arquitetura que lhe correspondia melhor aos seus anseios, além da ressonância dessa arquitetura em seu trabalho, ver Joseph: 1997.

$8 \mathrm{O}$ livro, "Module Proportion Symmetry, Rhythm", organizado por Gyorgy Kepes, conta com artigos sobre linguagem, artes visuais, biologia, matemática e dois sobre música: um, de Ernö Lendvai, trata das estratégias de simetria na música de Béla Bartók. O outro artigo é o de Cage. 
9 Sendo que no texto de 1966 há uma referência explícita à neutralidade destes novos meios para a criação musical - a qual em Schaeffer não é assumida, mas questionada.

10 Helmholtz, On the Sensation of Tone as a Physiological Basis for the Theory of Music.

11 Respectivamente, em "O Caminho para a Música Nova" e em "Harmonia".

12 Se tomarmos, por exemplo, String Quartet in Four Parts, de 1949, e Four, de 1989 - para quarteto de cordas - ambas possuem uma restrição contra o vibrato, sendo que se deve tocar sem ele.

13 Uma outra visão crítica desta relativa abertura à emancipação dos intérpretes, agora a partir do viés da sociologia da música, pode ser lido em Born (1995, p. 58), referindo-se à música experimental americana em geral: "A ênfase estava no processo da performance, sendo a música um ritual aberto e participativo, estruturado no tempo. Mas o compositor permanecia o autor destes eventos de modo que, ironicamente, a divisão do trabalho permanecia intacta".

\section{Referências}

BORN, Georgina. Rationalized Culture - IRCAM, Boulez, and the Institutionalization of the Musical Avant-Garde. Berkeley: University of California Press, 1995.

CAGE, John. "Rhythm Etc." In: KEPES, Gyorgy. Module Proportion Symmetry, Rhythm. New York: George Braziller, 1966.

CAGE, John. De segunda a um ano. Rio de Janeiro: Cobogó, 2013.

FENERICH, Alexandre. A Inscrição da Intimidade na Symphonie pour un Homme Seul. (tese). Doutorado em Musicologia. Universidade de São Paulo, São Paulo, 2012.

FLUSSER, Vilém. Filosofia da Caixa Preta - Ensaios para uma futura filosofia da fotografia. Rio de Janeiro: Dumará, 2012.

HELMHOLTZ, Hermann. On the Sensation of Tone as a Physiological Basis for the Theory of Music. New York: Courier Corporation, 1954.

JOSEPH, Branden W. "John Cage and the Architecture of Silence" In: October. Vol. 81, 1997. Boston: The MIT Press, 1997.

PALOMBINI, Carlos. "A Música Concreta Revisitada". In: Revista Eletrônica de Musicologia. Vol 4, Jun 1999. Departamento de Artes da UFPR, 1999.

PALOMBINI, Carlos. "Machines Songs V: Pierre Schaeffer - from Research Into Noises to Experimental Music". In: Computer Music Journal, 17:3, pp. 14-19, Fall 1993. MIT, 1993.

PALOMBINI, Carlos. "Pierre Schaeffer, 1953: por uma música experimental". In: Revista Eletrônica de Musicologia. Vol 3, Out. 1998. Departamento de Artes da UFPR, 1998.

POSSEBON, Ennio. "O Modulador de Le Corbusier: forma, proporção e medida na arquitetura." In: Revista de Cultura. v. único, p. 68-76. UniFMU), São Paulo, 2004.

SCHAEFFER, Pierre. À la Recherche d'une musique concrète. Paris: Seuil, 1952.

SCHAEFFER, Pierre. Machines à communiquer: I. Genèse des simulacres. Paris: Seuil, 1970.

SCHAEFFER, Pierre. Traité des Objets musicaux - Essai Interdisciplines. Paris: Seuil, 1966.

SCHOENBERG, Arnold. Harmonia. São Paulo: Editora UNESP, 1999.

WEBERN, Anton. O caminho para a música nova. São Paulo, Novas Metas, 1984. 